\title{
Electron-Induced Conversion of Silylones to Six-Membered Cyclic Silylenes
}

Sudipta Roy, ${ }^{\dagger}$ Kartik Chandra Mondal, ${ }^{\dagger}$ Lennard Krause, ${ }^{\dagger}$ Peter Stollberg, ${ }^{\dagger}$ Regine Herbst-Irmer, ${ }^{\dagger}$ Dietmar Stalke, ${ }^{* \dagger}{ }^{\dagger}$ Jann Meyer, ${ }^{\dagger}$ A. Claudia Stückl, ${ }^{\dagger}$ Bholanath Maity, ${ }^{\dagger}$ Debasis Koley, ${ }^{*}+\frac{+}{\dagger}$ Suresh Kumar Vasa, ${ }^{\S}$ Sheng Qi Xiang, ${ }^{\S}$ Rasmus Linser, ${ }^{\S}$ and Herbert W. Roesky*,†

${ }^{\dagger}$ Institut für Anorganische Chemie, Georg-August-Universität, Tammannstraße 4, 37077 Göttingen, Germany

${ }^{\ddagger}$ Department of Chemical Sciences, IISER-Kolkata, Mohanpur Campus, Mohanpur 741252, India

${ }^{\S}$ Abteilung für NMR-basierte Strukturbiologie, Max-Planck-Institut für Biophysikalische Chemie, Am Faßberg 11, 37077 Göttingen, Germany

\section{Supporting Information}

ABSTRACT: A silicon atom in the zero oxidation state stabilized by two carbene ligands is known as siladicarbene (silylone). There are two pairs of electrons on the silicon atom in silylone. This was recently confirmed by both experimental and theoretical charge density investigations. The silylone is stable up to $195^{\circ} \mathrm{C}$ in an inert atmosphere. However, a substoichiometric amount (33 mol\%) of potassium metal triggers the activation of the unsaturated $\mathrm{C}: \mathrm{Si}: \mathrm{C}$ backbone, leading to a selective reaction with a tertiary $\mathrm{C}-\mathrm{H}$ bond in an atom-economical approach to form a six-membered cyclic silylene with three-coordinate silicon atom. Cyclic voltammetry shows that this reaction proceeds via the formation of a silylone radical anion intermediate, which is further confirmed by EPR spectroscopy.

T $\mathrm{n}$ 1994, West et al. ${ }^{1}$ reported on the first N-heterocyclic silylene $\left(\mathrm{R}_{2} \mathrm{Si}\right)$ which is stable at room temperature (Scheme 1a). After this breakthrough, the chemistry of lowvalent silicon was explored more rapidly by various groups. ${ }^{2} \mathrm{~A}$ silylene in general is a molecule that contains a divalent neutral silicon atom having a lone pair of electrons at the silicon atom. ${ }^{1}$ Silylenes with three-coordinate silicon are also known ${ }^{2 a, c, d, e}$ (Scheme $1 \mathrm{c}-\mathrm{f}$ ). Some of these compounds can activate small molecules. ${ }^{3,4}$

In 2009, theoretical calculations on various $(\mathrm{NHC})_{2} \mathrm{Si}$ compounds, coined as silylones, showed that the synthesis of this class of compounds is experimentally feasible. ${ }^{5}$ Approximately two decades after the first report ${ }^{1}$ of silylene $\left(\mathrm{R}_{2} \mathrm{Si}:\right)$, the syntheses of silylones (cAAC) ${ }_{2} \mathrm{Si}$ with two-coordinate silicon were reported (cAAC = cyclic alkyl (amino) carbene, Scheme $1 \mathrm{~g}){ }^{6}$ Later on, a cyclic silylone (bNHC)Si (Scheme $1 \mathrm{~h}$ ) was prepared by Driess et al. ${ }^{7}$ Silylone features a silicon atom in the oxidation state zero which is stabilized by two carbene ligands. Consequently, this silicon atom contains two pairs of electrons. The silylone (or siladicarbene) is the heavier analogue of the carbodicarbene (carbene) ${ }_{2} \mathrm{C}^{8-10}$ Similarly, it also possesses two lone pairs of electrons at the central carbon atom, which are shown to form coordination bonds with acceptor molecules. So far, only metal complexes of carbo-
Scheme 1. (a-f) Representative Silylenes with Two- and Three-Coordinate Silicon, (g) Acyclic Silylones Stabilized by cAAC, and (h) Cyclic Silylones Stabilized by bNHC

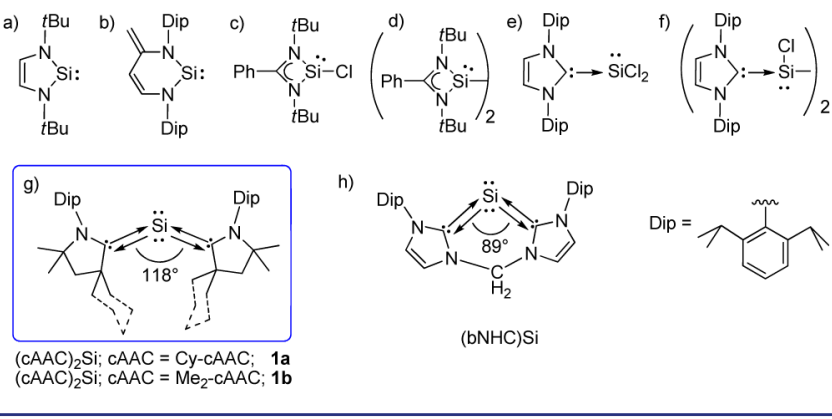

dicarbene are developed in connection with their reactivity. ${ }^{8-11}$ In contrast, on the reactivity of silylones, nothing has been known until now.

We have recently reported the synthesis of the dark bluecolored silylone (cAAC) ${ }_{2} \mathrm{Si}$, prepared from the diradical (cAAC) ${ }_{2} \mathrm{SiCl}_{2}$ under $\mathrm{KC}_{8}$ reduction, ${ }^{12 \mathrm{a}}$ and the related charge density investigations. ${ }^{12 \mathrm{~b}}$ The silicon atom of a silylone possesses one non-bonding lone pair, and the second pair of electrons participates in a three-center, two-electron $\pi$-bond between two carbene carbon atoms and the central silicon atom (C:Si:C). ${ }^{6 a}$ Thus, $\mathrm{Si}-\mathrm{C}$ bonds of silylones are very strong. This results in an unforeseen stability of these molecules. We have observed that crystalline silylones are stable in an inert atmosphere for about 2 years without any decomposition. They can be characterized by mass spectrometry (see Supporting Information (SI)). Silylones (1) are thermally stable up to $195{ }^{\circ} \mathrm{C}$, at which they melt to produce a blue liquid and decompose to a yellow liquid above $220^{\circ} \mathrm{C}$. Silylenes with a two-coordinate silicon atom can react with molecular hydrogen, ammonia, and carbon dioxide. ${ }^{3,4}$ In contrast, $(\mathrm{cAAC})_{2} \mathrm{Si}$ does not react with any of these gases at room temperature. Herein we report the first reactivity study of silylones generating cyclic silylenes with a three-coordinate silicon atom.

Received: October 10, 2014 
Considering the fact that cAAC is both a strong $\sigma$-donor and a $\pi$-acceptor, (cAAC) $)_{2} \mathrm{Si}$ might accept an electron at the unsaturated $\mathrm{C}: \mathrm{Si}: \mathrm{C}$ backbone, $(\mathrm{Cy}-\mathrm{cAAC})_{2} \mathrm{Si}$ (1a, Cy-cAAC = : $\left.\mathrm{C}\left(\mathrm{CH}_{2}\right)\left(\mathrm{CMe}_{2}\right)\left(\mathrm{C}_{6} \mathrm{H}_{10}\right) \mathrm{N}-2,6-i \mathrm{Pr}_{2} \mathrm{C}_{6} \mathrm{H}_{3}\right)$ was investigated by cyclic voltammetry $(\mathrm{CV})$ in $0.1 \mathrm{M}\left[n-\mathrm{Bu}_{4} \mathrm{~N}\right] \mathrm{PF}_{6}$ THF solution. Fortunately, the $\mathrm{CV}$ showed a quasi-reversible reduction at $E_{1 / 2}$ $=-1.55 \mathrm{~V}$ (referred against $\mathrm{Cp} *{ }_{2} \mathrm{Fe} / \mathrm{Cp}^{*}{ }_{2} \mathrm{Fe}^{+}$), indicating the formation of a radical anion $1 \mathbf{a}^{\circ-}$. In addition, the measurement showed three irreversible reductions $(E=-1.07,-2.39$, and $-2.72 \mathrm{~V}$, see SI). Based on the quasi-reversible nature of the $\mathrm{CV}$ we anticipated a possible rearrangement of the intermediate radical anion and accordingly a chemical reaction was set up. THF was added at room temperature to a 1:1 molar solid-state mixture of (Cy-cAAC $)_{2} \mathrm{Si}(\mathbf{1 a})$ and metallic potassium via a cannula. The resultant dark blue solution was stirred for $20 \mathrm{~min}$ to obtain a dark green solution which further turned to greenish-yellow solution within the next $15 \mathrm{~min}$ of additional stirring. The solution was filtered to separate the unreacted potassium $(67 \mathrm{~mol} \%)$, indicating $33 \mathrm{~mol} \%$ of potassium was consumed during the reaction. The THF solution was concentrated and stored at $-32{ }^{\circ} \mathrm{C}$ in a freezer to form bright yellow blocks of $2 \mathrm{a}$ in $80 \%$ yield. The analogous compound $\mathbf{2 b}$ was prepared from the precursor $\left(\mathrm{Me}_{2}-\mathrm{cAAC}\right)_{2} \mathrm{Si}(\mathbf{l b})$ (see SI). The X-ray single-crystal diffractions revealed that $\mathbf{2 a , b}$ are isomers of the silylones $\mathbf{1} \mathbf{a}, \mathbf{b}$, respectively. The transformation of $\mathbf{1 a}, \mathbf{b}$ into $\mathbf{2 a}, \mathbf{b}$ can be rationalized as one of the $\mathrm{H}-\mathrm{CMe}_{2}$ groups (1a,b) has selectively reacted (Scheme 2) with one $\mathrm{C}_{\mathrm{cAAC}}-\mathrm{Si}$ bond, producing $\mathrm{H}-\mathrm{C}_{\mathrm{cAAC}}-\mathrm{Si}\left(\mathrm{CMe}_{2}\right)$ moiety in products $2 \mathbf{a}, \mathbf{b}$, respectively.

Scheme 2. Conversion of Silylone with Two-Coordinate Silicon to Silylene with Three-Coordinate Silicon

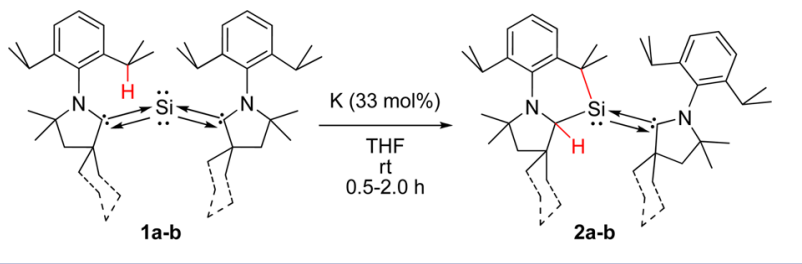

The solutions of $\mathbf{2 a}, \mathbf{b}$ are stable at $0{ }^{\circ} \mathrm{C}$ for about 2 months. The crystals of $\mathbf{2} \mathbf{a}, \mathbf{b}$ are stable at room temperature for more than 1 month in an inert atmosphere. They $(\mathbf{2} \mathbf{a}, \mathbf{b})$ melt in the temperature range of $223-224{ }^{\circ} \mathrm{C}$ and $211-212{ }^{\circ} \mathrm{C}$, respectively, while the melting range of $\mathbf{1 a}, \mathbf{b}$ is $194-195{ }^{\circ} \mathrm{C}$. Compounds $\mathbf{2 a , b}$ were also characterized (see SI) by mass spectrometry $(\mathrm{m} / z(100 \%): 678.4(\mathbf{2 a}), 598.4(\mathbf{2 b}))$. The ${ }^{29} \mathrm{Si}$ NMR spectra of $\mathbf{2 a , b}$ exhibit resonances at 55.98 and 54.55 ppm, respectively, which are upfield-shifted when compared to those of $1 \mathbf{a}, \mathbf{b}(71.15$ and $66.71 \mathrm{ppm})$. The ${ }^{13} \mathrm{C}$ NMR spectra of 2a,b show resonances at $69.4(\mathrm{CH}) / 173.5(\mathrm{C}:)$ and $66.2(\mathrm{CH}) /$ 172.1(C:) ppm, respectively, which are upfield-shifted when compared to those of $\mathbf{1 a , b}(210.8$ and $210.9 \mathrm{ppm}) .^{6 \mathrm{a}, \mathrm{b}}$ The absence of ${ }^{1} \mathrm{H}$ nuclei directly bonded to $\mathrm{Si}$ of $\mathbf{2 a}$ is confirmed by a slow solid-state NMR cross-polarization buildup identical to 1a. A reduced CSA, however, confirms the more symmetrical distribution of electron density around the $\mathrm{Si}$ in $\mathbf{2 a}$ than in $\mathbf{1 a}$ (see SI). The unsymmetrical electronic environment of the ${ }^{29} \mathrm{Si}$ center in 1a resulting from the lone pair creates a strong chemical shift anisotropy (CSA, see SI). The UV-vis spectra of yellow-colored $\mathbf{2 a}, \mathbf{b}$, recorded in $n$-hexane, show absorption bands at $423 / 420 \mathrm{~nm}$ (see SI), while dark blue-colored silylones 1a,b exhibit bands at 575/570 and 618/611 nm, respectively. ${ }^{6 \mathrm{a}, \mathrm{b}}$

2a,b were both characterized by X-ray single-crystal determinations. The structural aspects of $\mathbf{2 a}$ are described herein (see SI for $\mathbf{2 b}$ ). Compound $\mathbf{2 a}$ crystallizes in the space group $P 2_{1} / n$. The silicon atom adopts a distorted trigonal pyramidal geometry which is bound to three carbon atoms including the central carbon atom of the former $i$ Pr substituent. The selected bond lengths and angles are given in the caption of Figure 1. The structure of 2 a shows that one carbene carbon

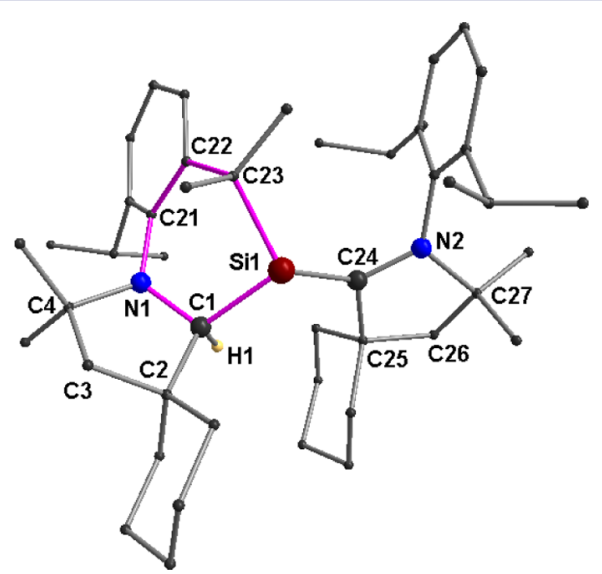

Figure 1. Molecular structure of $\mathbf{2 a}$. $\mathrm{H}$ atoms are omitted for clarity, except the freely refined H1. Selected experimental [calculated at the BP86/def2-SVP level for the ground state] bond lengths ( $\AA$ ) and angles $\left({ }^{\circ}\right)$ : Sil-C1 1.952(2) [1.948], Sil-C24 1.824(2) [1.809], Sil-C23 1.961(2) [1.968], C1-N1 1.461(3) [1.465], C24-N2 1.383(3) [1.374]; C23-Sil-C1 101.77(10) [100.67], C2-C1-N1 104.55(17) [105.98], C2-C1-Si1 120.81(16) [118.55], N1-C1-Si1 111.66(15) [111.17], C23-Sil-C24 126.42(10) [127.11], C24-Si1C1 112.70(10) [114.30], C25-C24-Sil 122.39(15) [122.05], N2C24-Si1 129.72(17) [129.95], C25-C24-N2 106.16(18) [106.93], C4-N1-C1 114.54(17) [112.91], C21-N1-C1 120.98(17) [122.46], C24-N2-C27 113.51(18) [113.46].

atom ( $\mathrm{C} 1)$ contains one proton, and the silicon atom is additionally bonded to the $\mathrm{CMe}_{2}$ group (C23) of one of the former isopropyl groups $\left(\mathrm{CHMe}_{2} ; \mathrm{C} 23-\mathrm{Sil}=1.961(2) \AA\right)$. This result shows that one of the $\mathrm{Me}_{2}(\mathrm{Ar}) \mathrm{C}-\mathrm{H}$ groups selectively reacted across one of the $\mathrm{C}_{\mathrm{cAAC}}-\mathrm{Si}$ bonds. The $\mathrm{C} 1-$ Sil and $\mathrm{C} 1-\mathrm{N} 1$ bonds are elongated from $1.8404(11)$ to $1.952(2) \AA$ and from $1.3827(15)$ to $1.461(3) \AA$, respectively, while the $\mathrm{C} 24\left(\mathrm{C}_{\mathrm{CAAC}}\right)-\mathrm{Si} 1$ and $\mathrm{C} 24-\mathrm{N} 2$ bond distances remain very close to the values $\left(\mathrm{C}_{\mathrm{cAAC}}-\mathrm{Si}=1.8535(12) \AA\right.$, C24-N2 = 1.3724(14) $\AA$ ) of silylone 1a. Finally, a new sixmembered ring containing two heteroatoms (shown in purple color in Figure 1) has been formed. The $\mathrm{C} 1-\mathrm{Si} 1-\mathrm{C} 23$ bond angle of $2 \mathrm{a}$ is $101.77(10)^{\circ}$, while the $\mathrm{C} 1-\mathrm{Si} 1-\mathrm{C} 24$ angle has changed from $118.16(5)^{\circ}$ to $112.70(10)^{\circ}$ when compared with that of precursor $1 \mathrm{a}$.

The Sil atom is $0.48 \AA$ above the $\mathrm{C} 1-\mathrm{C} 23-\mathrm{C} 24$ plane, while $\mathrm{C} 24$ is located only $0.12 \AA$ above the Sil-C25-N2 plane. All the bond parameters suggest that $2 \mathrm{a}$ might be a singlet diradical (as shown in SI Figure S12) containing one radical each on Si1 and $\mathrm{C} 24$ atoms $(\mathrm{Si} 1-\mathrm{C} 24=1.824(2) \AA)$. Similar $\mathrm{Si}-\mathrm{C}$ bond distances are observed in the monoradical (Cy-cAAC $\left.{ }^{\bullet}\right) \mathrm{SiCl}_{3}$ $(181.93(8))^{13}$ and diradical (Cy-cAAC $)_{2} \mathrm{SiCl}_{2} \quad(1.854(2)$, $1.843(2) \AA)$. The $\mathrm{C}_{\text {cAAC }}-\mathrm{N}$ bond distance of $2 \mathrm{a}$ is $1.38 \AA$, close to that of monoradical $\left(\mathrm{Cy}-\mathrm{cAAC}^{\bullet}\right) \mathrm{SiCl}_{3}(138.27(10)$ 
$\AA)^{13}$ and slightly smaller than those of $\mathrm{SiCl}_{2}$-bridged singlet diradical $\left(\mathrm{Cy}^{-\mathrm{cAAC}}\right)_{2} \mathrm{SiCl}_{2}$ (1.400(2), 1.403(2) Å). ${ }^{6 \mathrm{~b}}$

The stronger $\pi$-acceptor property ${ }^{13-15}$ of cAAC over NHC ( $\mathrm{N}$-heterocyclic carbene) is the reason why cAAC transfers the electron density from the silicon atom of cAAC- $\mathrm{SiCl}_{2}$ to the carbene carbon atom producing a singlet 1,2-diradical (SI Scheme S1a) which dimerizes to form a stable singlet 1,4diradical $\left(\mathrm{cAAC}^{\bullet}\right)_{2} \mathrm{Si}_{2} \mathrm{Cl}_{4}$ (SI Scheme $\left.\mathrm{S} 1 \mathrm{~b}\right) .{ }^{16}$ In contrast, the $\mathrm{NHC}$ analogue $(\mathrm{NHC}) \mathrm{SiCl}_{2}$ is a singlet non-radical species ${ }^{2 \mathrm{e}}$ which is stable and isolable in the monomeric form. Based on our previous results and present comparisons, it can be argued that cAAC may destabilize the lone pair of electrons of $\mathbf{2} \mathbf{a}, \mathbf{b}$ on the silicon atom in the oxidation state 2 . Hence, it is intriguing whether 2a,b possess singlet 1,2-diradical ground states (SI Figure S12).

We have performed DFT calculations at the U/R-M06-2X/ SVP level of theory (see SI) to illustrate the electronic structure and bonding of $\mathbf{2 a}$. The closed-shell singlet electronic state is lower in energy by $16.8 \mathrm{kcal} / \mathrm{mol}\left(\Delta G_{\mathrm{L}}^{\mathrm{S}}\right.$, at U/R-M06-2X/ $\mathrm{TZVP} / / \mathrm{U} / \mathrm{R}-\mathrm{M} 06-2 \mathrm{X} / \mathrm{SVP}$ level) than its triplet form. Geometry optimization with broken symmetry formalism reveals that the diradical singlet state again is higher in energy than the closed-shell singlet state by $14.5 \mathrm{kcal} / \mathrm{mol}\left(\Delta G_{\mathrm{L}}{ }^{\mathrm{S}}\right)$. The optimized geometrical parameters of the singlet state are in much better agreement to the crystal structure of $2 \mathrm{a}$ than its diradical singlet or triplet states (see SI Figure S12 and Table S3). Moreover for further validation, $\operatorname{CASSCF}(2,2) / \operatorname{SVP}$ calculation was performed at the M06-2X/SVP optimized geometry. The coefficient values are $0.96,0.0$, and -0.29 for the corresponding electronic configurations of $(2,0),(1,1)$, and $(0,2)$, respectively. Additionally the diagonal elements of the final one-electron symbolic density matrix are 1.8 and 0.2 , confirming the closed-shell singlet state to be the ground state of 2a. The Sil-C24 bond is significantly shorter (1.81 $\AA$ ) than its (cAAC) $)_{2} \mathrm{Si}$ isomer, $1 \mathrm{a}(1.85 \AA)$ due to the stronger $\pi$-bond character $(\operatorname{HOMO}(\mathbf{1 a}), S I$ Figure S13a). This $\pi$-bond is polarized toward Sil (Si1, 39\%; C24, 21\%; N2, 15\%) due to the sharing of the lone pair of electrons from N2 to C24 (NPA charge, $q_{\mathrm{N} 1}=-0.527 e, q_{\mathrm{N} 2}=-0.498 e$, SI Table S4). Unlike the silylone $\left((\mathrm{cAAC})_{2} \mathrm{Si}\right),{ }^{\mathrm{b}, 12 \mathrm{~b}}$ no lone pair is found on either $\mathrm{Sil}$ or $\mathrm{C} 24$ in $2 \mathrm{a}$. The bonding scenario of the $\mathrm{Sil}=\mathrm{C} 24$ bond in 2a was further elucidated by QTAIM calculations. ${ }^{17}$ The important topological parameters at the $(3,-1)$ bond critical points (BCPs) are given in SI Table S3. The covalent nature of the $\mathrm{Sil}=\mathrm{C} 24$ bond is characterized with electron density $[\rho(r)]$ of 0.11 and Laplacian $\left[\nabla^{2} \rho(r)\right]$ of +0.42 at the respective BCP (for details see SI). Furthermore, the high ellipticity value $(\varepsilon=0.51)$ suggests a significant double bond character, supporting the NBO calculations discussed before. The delocalization index (DI) value of 0.99 is close to the value (1.17) of the $\mathrm{Si}=\mathrm{C}$ double bond in $\mathrm{H}_{2} \mathrm{Si}=\mathrm{CH}_{2},{ }^{18}$ which indicates the presence of a strengthened $\mathrm{Sil}=\mathrm{C} 24 \pi$-bond, ${ }^{19}$ pointing toward a stronger $\mathrm{Si} \rightarrow \mathrm{C}$ back-donation in $2 \mathrm{a}$ compared to $(\mathrm{cAAC})_{2} \mathrm{Si}$. The $\mathrm{Si}-\mathrm{C}$ bond distances of $\mathbf{2 a} \mathbf{a} \mathbf{b}$ are between single and double silicon-carbon bonds. Therefore $\mathbf{2} \mathbf{a}, \mathbf{b}$ can also be considered as silenes, when only reflected on the $\mathrm{Si}-\mathrm{C}$ bond length.

The proposed mechanism for the transformation of $\mathbf{1 a}, \mathbf{b}$ to $\mathbf{2} \mathbf{a}, \mathbf{b}$ is shown in Scheme 3. CV of $\mathbf{1} \mathbf{a}, \mathbf{b}$ suggests the formation of very reactive radical anion intermediates, $(\mathbf{1} \mathbf{a}, \mathbf{b})^{\bullet-}$, via oneelectron transfer from potassium to $\mathbf{1} \mathbf{a}, \mathbf{b}$. The formation of the radical anion $\left(\mathbf{1 b}^{\mathbf{}}\right)$ was further confirmed by ESR spectroscopy (see SI). The radical electron of $(\mathbf{1} \mathbf{a}, \mathbf{b})^{\bullet-}$ resides on one
Scheme 3. Proposed Mechanistic Pathway for the Formation of 2a from 1a

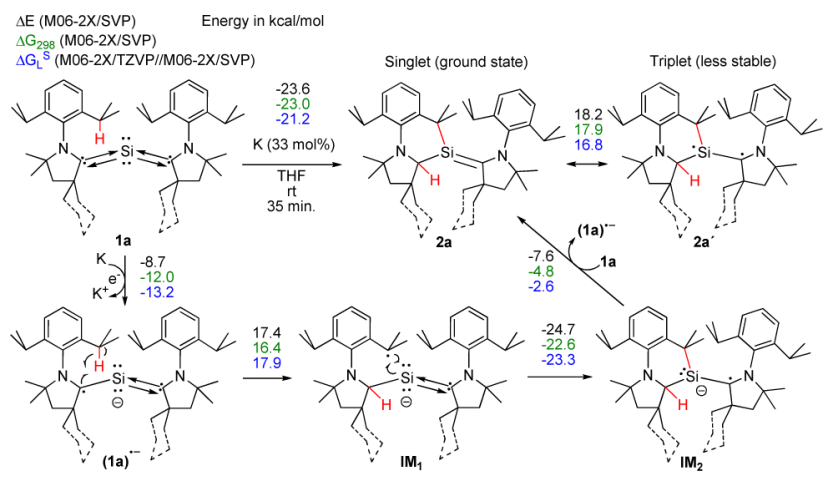

of the carbene carbon atoms and abstracts one $\mathrm{H}^{\bullet}$ from the $\mathrm{H}$ $\mathrm{CMe}_{2}$ group of a cAAC, producing $\left(\mathrm{IM}_{1}\right)-\mathrm{C}\left({ }^{\bullet}\right) \mathrm{Me}_{2}$, which further reacts with the central silicon atom to form $\mathbf{I M}_{2}$, which leaves the electron at the end of the cycle to form the products $\mathbf{2 a}, \mathbf{b}$. Formation of the radical anion intermediates $(\mathbf{1} \mathbf{a}, \mathbf{b})^{\bullet-}$ is the key step for the activation of the very strong $\mathrm{C}-\mathrm{H}$ bond. In comparison, low-valent transition metals often activate $\mathrm{C}-\mathrm{H}$ bonds via donation of electron density from their filled $\mathrm{d}$ orbitals to a $\sigma^{*}$ orbital of the $\mathrm{C}-\mathrm{H}$ bond. We have explored the probable mechanism on the basis of a DFT study. The chemical transformation 1a $\rightarrow$ 2a (SI Table S5) is initiated by the reduction of 1a in the presence of metallic potassium, leading to the stable radical anion, $(\mathbf{1 a})^{\bullet-}\left(\Delta G_{\mathrm{L}}{ }^{\mathrm{S}}=-13.2 \mathrm{kcal} / \mathrm{mol}\right)$. The radical electron is accommodated in the p orbitals of the carbene carbon atoms (see the LUMO (1a) and SOMO (1a) ${ }^{\bullet-}$ in SI Figure S14a). The Mulliken spin density plot of the radical anion shows that the unpaired electron is delocalized (Figure 2)

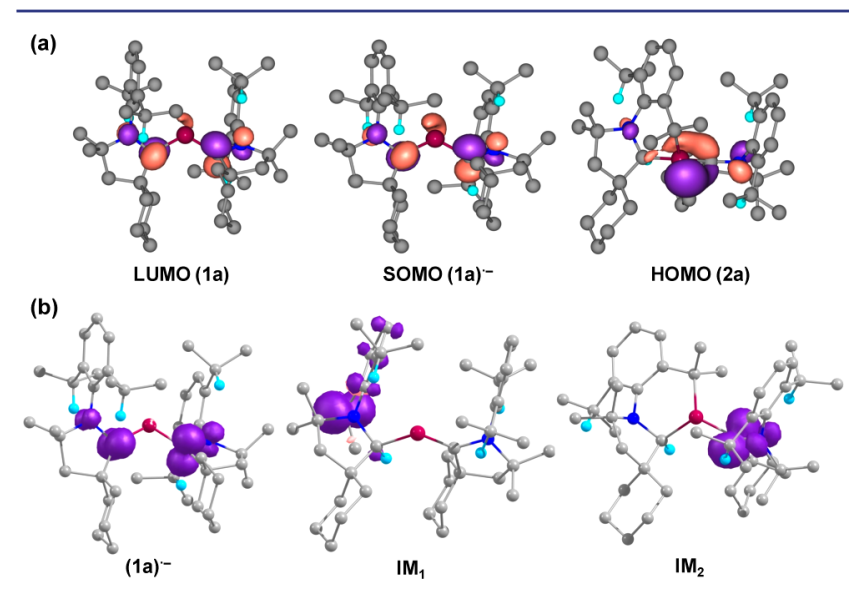

Figure 2. Computed (a) KS-MO and (b) Mulliken spin density plot of selective intermediates (isosurface $=0.006 \mathrm{au}$ ) at U/R-M06-2X/ TZVP//U/R-M06-2X/SVP level. Hydrogen atoms are omitted for clarity.

between two carbene carbon atoms ( $\mathrm{C} 1$ and $\mathrm{C} 24)$ via the vacant d-orbital of the silicon atom (SI Figure S14b). The $(\mathbf{1 a})^{\bullet-} \rightarrow \mathbf{I M}_{1}$ transformation is highly endergonic $\left(\Delta G_{\mathrm{L}}{ }^{\mathrm{S}}=\right.$ $17.9 \mathrm{kcal} / \mathrm{mol}$ ) since the unpaired electron is shifted to the $-\mathrm{CMe}_{2}$ of the Dip group (IM 1 , SI Figure S14b).

The extra stability of the $(\mathbf{1 a})^{\bullet-}$ system is due to the delocalization of the unpaired electron and is quantified by model study shown in SI Scheme S2. The next step $\mathbf{I M}_{\mathbf{1}} \rightarrow \mathbf{I M}_{\mathbf{2}}$ is now exergonic $\left(\Delta G_{\mathrm{L}}{ }^{\mathrm{S}}=-23.3 \mathrm{kcal} / \mathrm{mol}\right)$ because the radical 
electron resides in the $\mathrm{p}$ orbital of the carbene carbon atom (C24) bonded to the silicon atom (see Mulliken spin density in $\mathbf{I M}_{2}$, SI Figure S14b). Finally, $\mathbf{I M}_{2}$ is oxidized to the product $\mathbf{2 b}$ along with simultaneous reduction of another 1a species $\left(\Delta G_{\mathrm{L}}{ }^{\mathrm{S}}\right.$ $=-2.6 \mathrm{kcal} / \mathrm{mol})\left(\right.$ SI Table S5). ${ }^{20}$

In conclusion, we have shown that a substoichiometric amount $(33 \mathrm{~mol} \%)$ of potassium triggers the activation of the unsaturated $\mathrm{C}_{\text {carbene }}: \mathrm{Si}: \mathrm{C}_{\text {carbene }}$ backbone of very stable silylones $\mathbf{1 a}, \mathbf{b}$, leading to a selective reaction with one intramolecular tertiary $\mathrm{C}-\mathrm{H}$ bond in an atom-economical approach to form the isomers $\mathbf{2 a , b}$ with a three-coordinate silicon atom. This is the first report on the reactivity studies of silylones. CV suggests that silylone can quasi-reversibly accept an electron to form a very reactive radical anion intermediate, $(\mathbf{1} \mathbf{a}, \mathbf{b})^{\bullet-}$, which rationalizes the reaction of one of the $\mathrm{C}-\mathrm{H}$ bonds across $\mathrm{C}_{\text {carbene }}=\mathrm{Si}$ even at room temperature. The energetics of the reaction is computed to be favorable under the given reaction condition, which is important for activation of strong bonds by zero-valent group 14 elements. The electronic structure and bonding properties of the product containing a threecoordinate silicon atom were studied by theoretical calculations, which revealed that it possesses a closed-shell singlet ground state.

\section{ASSOCIATED CONTENT}

\section{S Supporting Information}

Syntheses of 2a,b; UV-vis, crystal structure determination, CV, EPR, and theoretical details. This material is available free of charge via the Internet at http://pubs.acs.org.

\section{AUTHOR INFORMATION}

\section{Corresponding Authors}

dstalke@chemie.uni-goettingen.de

koley@iiserkol.ac.in

hroesky@gwdg.de

Notes

The authors declare no competing financial interest.

\section{ACKNOWLEDGMENTS}

Dedicated to Prof. Didier Astruc on the occasion of his 68th birthday. We thank Prof. F. Mayer for EPR. H.W.R. thanks the Deutsche Forschungsgemeinschaft (DFG RO 224/60-I) for financial support. D.K. acknowledges the IISER-Kolkata for start-up grant and SERB for DST fellowship (SR/FT/CS-72/ 2011). D.S. acknowledges partial funding from the DNRFfunded CMC (DNRF93).

\section{REFERENCES}

(1) Denk, M.; Lennon, R.; Hayashi, R.; West, R.; Belyakov, A. V.; Verne, H. P.; Haaland, A.; Wagner, M.; Metzler, N. J. Am. Chem. Soc. 1994, 116, 2691-2692.

(2) (a) So, C.-W.; Roesky, H. W.; Magull, J.; Oswald, R. B. Angew. Chem., Int. Ed. 2006, 45, 3948-3950; Angew. Chem. 2006, 118, 40524054. (b) Driess, M.; Yao, S.; Brym, M.; Wüllen, C. v.; Lentz, D. J. Am. Chem. Soc. 2006, 128, 9628-9629. (c) Wang, Y.; Xie, Y.; Wei, P.; King, R. B.; Schaefer, H. F., III; Schleyer, P. v. R.; Robinson, G. H. Science 2008, 321, 1069-1071. (d) Sen, S. S.; Jana, A.; Roesky, H. W.; Schulzke, C. Angew. Chem., Int. Ed. 2009, 48, 8536-8538; Angew. Chem. 2009, 121, 8688-8690. (e) Ghadwal, R. S.; Roesky, H. W.; Merkel, S.; Henn, J.; Stalke, D. Angew. Chem., Int. Ed. 2009, 48, 56835686; Angew. Chem. 2009, 121, 5793-5796. (f) Lee, V. Ya.; Sekiguchi, A. Organometallic Compounds of Low-Coordinate $\mathrm{Si}, \mathrm{Ge}, \mathrm{Sn}$ and $\mathrm{Pb}$ : From Phantom Species to Stable Compounds; Wiley: New York, 2010.
(3) (a) Mandal, S. K.; Roesky, H. W. Chem. Commun. 2010, 46, 6016-6041. (b) Sen, S. S.; Khan, S.; Nagendran, S.; Roesky, H. W. Acc. Chem. Res. 2012, 45, 578-587. (c) Bolm, B.; Driess, M. In Functional Molecular Silicon Compounds II; Scheschkewitz, D., Ed.; Structure and Bonding 156; Springer: Berlin, 2014; pp 85-123.

(4) Ghadwal, R. S.; Azhakar, R.; Roesky, H. W. Acc. Chem. Res. 2013, 46, 444-456.

(5) (a) Takagi, N.; Shimizu, T.; Frenking, G. Chem.-Eur. J. 2009, 15, 8593-8604. (b) Takagi, N.; Shimizu, T.; Frenking, G. Chem.Eur. J. 2009, 15, 3448-3456.

(6) (a) Mondal, K. C.; Roesky, H. W.; Schwarzer, M. C.; Frenking, G.; Niepötter, B.; Wolf, H.; Herbst-Irmer, R.; Stalke, D. Angew. Chem., Int. Ed. 2013, 52, 2963-2967; Angew. Chem. 2013, 125, 3036-3040. (b) Mondal, K. C.; Samuel, P. P.; Tretiakov, M.; Singh, A. P.; Roesky, H. W.; Stückl, A. C.; Niepötter, B.; Carl, E.; Wolf, H.; Herbst-Irmer, R; Stalke, D. Inorg. Chem. 2013, 52, 4736-4743.

(7) Xiong, Y.; Yao, S.; Inoue, S.; Epping, J. D.; Driess, M. Angew. Chem., Int. Ed. 2013, 52, 7147-7150; Angew. Chem. 2013, 125, 72877291.

(8) Tonner, R.; Öxler, F.; Neumüller, B.; Petz, W.; Frenking, G. Angew. Chem., Int. Ed. 2006, 45, 8038-8042; Angew. Chem. 2006, 118 , 8206-8211.

(9) Dyker, C. A.; Lavallo, V.; Donnadieu, B.; Bertrand, G. Angew. Chem. 2008, 120, 3250-3253; Angew. Chem., Int. Ed. 2008, 47, 32063209.

(10) (a) Fürstner, A.; Alcarazo, M.; Goddard, R.; Lehmann, C. W. Angew. Chem., Int. Ed. 2008, 47, 3210-3214; Angew. Chem. 2008, 120, 3254-3258. (b) Alcarazo, M.; Lehmann, C. W.; Anoop, A.; Thiel, W.; Fürstner, A. Nat. Chem. 2009, 1, 295-301.

(11) See SI (S18-S21) for coordination compounds of carbodicarbene.

(12) (a) Mondal, K. C.; Roesky, H. W.; Schwarzer, M. C.; Frenking, G.; Tkach, I.; Wolf, H.; Kratzert, D.; Herbst-Irmer, R.; Niepötter, B.; Stalke, D. Angew. Chem., Int. Ed. 2013, 52, 1801-1805; Angew. Chem. 2013, 125, 1845-1850. (b) Niepötter, B.; Herbst-Irmer, R.; Kratzert, D.; Samuel, P. P.; Mondal, K. C.; Roesky, H. W.; Jerabek, P.; Frenking, G.; Stalke, D. Angew. Chem., Int. Ed. 2014, 53, 2766-2770; Angew. Chem. 2014, 126, 2806-2811.

(13) Mondal, K. C.; Roesky, H. W.; Stückl, A. C.; Ehret, F.; Kaim, W.; Dittrich, B.; Maity, B.; Koley, D. Angew. Chem., Int. Ed. 2013, 52, 11804-11807; Angew. Chem. 2013, 125, 12020-12023.

(14) Mondal, K. C.; Samuel, P. P.; Roesky, H. W.; Aysin, R. R.; Leites, L. A.; Neudeck, S.; Lübben, J.; Dittrich, B.; Hermann, M.; Frenking, G. J. Am. Chem. Soc. 2014, 136, 8919-8922.

(15) (a) Martin, D.; Soleilhavoup, M.; Bertrand, G. Chem. Sci. 2011 2, 389-399. (b) Martin, C. D.; Soleilhavoup, M.; Bertrand, G. Chem. Sci. 2013, 4, 3020-3030 and references therein.

(16) Mondal, K. C.; Dittrich, B.; Maity, B.; Koley, D.; Roesky, H. W. J. Am. Chem. Soc. 2014, 136, 9568-9571.

(17) Bader, R. F. W. Atoms in Molecules. A Quantum Theory; Clarendon Press: Oxford, 1990.

(18) Chesnut, D. B. Chem. Phys. 2001, 271, 9-16.

(19) (a) Mondal, K. C.; Roesky, H. W.; Dittrich, B.; Holzmann, N.; Hermann, M.; Frenking, G.; Meents, A. J. Am. Chem. Soc. 2013, 135, 15990-15993. (b) Majumdar, M.; Huch, V.; Bejan, I.; Meltzer, A.; Scheschkewitz, D. Angew. Chem., Int. Ed. 2013, 52, 3516-3520; Angew. Chem. 2013, 125, 3601-3605.

(20) For the step $\mathrm{IM}_{2} \rightarrow \mathbf{2 a}$, the reduction of $\mathbf{1 a}$ is more favored than the step $\mathrm{K}^{+} \rightarrow \mathrm{K}$ by $13.2 \mathrm{kcal} / \mathrm{mol}\left(\Delta G_{\mathrm{L}}{ }^{\mathrm{S}}\right)$. 